The Social Sciences 6 (4): 323-327, 2011

ISSN: $1818-5800$

(C) Medwell Journals, 2011

\title{
A Development of a Blended Learning Model for Learning an Information Technology for Life Course of Undergraduate Students at Rajabhat University
}

\author{
Thipphanet Khantapthai, Chaiyot Ruangsuwan and Paitool Suksringarm \\ Faculty of Education, Mahasarakham University, 44000 Mahasarakham, Thailand
}

\begin{abstract}
This research aimed to develop and study the implementation of the Blended learning model for learning an information technology for life course of undergraduate students at Rajabhat University. The research was divided into three phases: phases 1, a synthesis of the blended learning system models; phases 2, a development of the Blended learning model and phases 3, an evaluation of a implementation of the developed Blended learning model. The sample of 281 of undergraduate students at Surindra Rajabhat University participated in the study and they were randomly assigned to an experimental group with 151 students learned using the developed model and a control group with 130 students learned using the conventional learning approach. These students were selected using a cluster random sampling technique. The research instruments included 11 plans of learning teaching organization, an learning achievement test with 60 items, a scale on self directed learning behaviors with 29 items and a critical thinking test with 40 items. The collected data were analyzed using a percentage, a mean, a standard deviation and for testing hypotheses the paired t-test and the F-test (two-way MANCOVA and two-way ANCOVA) were employed. The study results are as following: the developed Blended learning model consisted of four components: principle of blended learning, model objectives, organization of learning activities and measurement and evaluation. The component of an organization of blended learning activities had three activities: self learning program, class learning using interactive lectures and self-learning with on-line lessons. The developed Blended learning model showed an efficiency of 82.07/80.39 and effectiveness index of 0.6527. The students indicated gains in learning achievement, critical thinking as a whole and in each of five subscales and self-directed learning behaviors as a whole and in each of five subscales from before learning via the developed model $(\mathrm{p}<0.0001)$. The experimental group students showed more learning achievement, critical thinking in general and in three subscales: inference, recognition of assumptions and evaluation of arguments and self-directed learning behaviors in general and in five subscales than did the control group students $(\mathrm{p}<0.05)$. The students from different faculties did not differently indicate learning achievement, critical thinking in general and in two subscales: inference and recognition of assumptions. Otherwise, the students from science and technology faculty showed more critical thinking in three subscales: deduction, interpretation and evaluation of arguments than did the students from education faculty and humanities and social sciences Faculty and evidenced more self-directed learning behaviors in general and in four subscales, except for the learning evaluation subscale than did those students from other faculties $(\mathrm{p}<0.05)$. The statistical interactions of learning model and faculties on learning achievement, critical thinking in general and three subscales: deduction, interpretation and evaluation of arguments and self-directed learning behaviors in general and three subscales formulating learning objectives, planning study and evaluating learning outcomes $(\mathrm{p}<0.05)$.
\end{abstract}

Key words: Blended learning, information technology, life course, undergraduate student, Rajabhat University, development, Thialand

\section{INTRODUCTION}

University is considered as a source of community learning. Today's technologies are applied in the operation to increase the efficiency of the agency in all areas, especially in the teaching and learning activities. A modified method of teaching at the university level in several ways. As the technology becomes important and necessary part of the university. The forms of electronic learning. Ideas for reducing costs of education. And solving the problem of insufficient personnel (Jongchaikit, 2003). Teaching and learning in a traditional

Corresponding Author: Thipphanet Khantapthai, Faculty of Education, Mahasarakham University, 44000 Mahasarakham, Thailand 
lecture, this course is based on the main. The activities of teaching and learning in the classroom that teachers and learners must be ready to face. Teaching model is to meet each other. Learner's attention only during the 1 st $20 \mathrm{~min}$ and then gradually fade away. Until a new activation, learning to listen and watch this alone, not fun. Teachers must try to ask questions, trying to keep the question or try to help the students to have involved in teaching and learning activities.

In addition, teachers try to help the students understand and remember main knowledge. If teachers are gifted in teaching can do better. But generally can not proceed as expected. In teaching and learning activities, the key one is how to enable students understand, how to make the students eager to learn. So in teaching today, teachers should consider how various forms that will enable students to achieve the goal of learning more effectively. Students should be learn in a variety of format, appropriate have modern lessons, enhance the learning process to work, techniques to assist students in learning. This will allow the students to desired behavior is as expected in learning and teaching activities. There presented for teaching and learning in a format that focuses on students is more important.

Such as blended learning to bring the advantages of each format to use to solve the problem both in class and online practice such as in the laboratory, group activities is strengths of each model in addition to the weaknesses of the other.

In addition to this, blended learning is model for integrating online learning and face-to-face meetings together will enable students to interact and collaborate ideas. Have relationship between the students together be caused by an interaction in the group that have placement of group work as well with technology to help before and/or after the study that instructors meet with students (Jinjo, 2007).

\section{The research's purposes:}

- To develop Blended learning model for learning Information Technology (IT) for life course of undergraduate students at Rajabhat University

- To study the implementation of the Blended learning model for learning an Information Technology (IT) for life course of undergraduate students at Rajabhat University

\section{MATERIALS AND METHODS}

This study is research and development. The researcher conducting research into three phases as follows:
Phase 1: Study the synthetic Blended learning model for learning Information Technology (IT) for life course of undergraduate students at Rajabhat University:

- Step 1 contextual study: Aimed to study learning and teaching information technology for life course

- Step 2 conceptual study: Aimed to analytical framework tutorial an Information Technology (IT) for life course. To documentary analysis were the organized teaching and learning in higher education, Blended learning model, critical thinking, self-directed learning. The teaching and learning activities using the learning cycle $5 \mathrm{E}$, development of Blended learning model, evaluation Blended learning model and research-related Blended learning model, critical thinking and self directed learning

Phase 2: Study to develop Blended learning model for learning an Information Technology (IT) for life course of undergraduate students at Rajabhat University. The data from the study, analytical, synthesis principles and theories related forms Blended learning model for learning Information Technology (IT) for life course from the research in phase 1 to the Draft Blended learning model:

- The conceptual framework

- The Draft Blended learning model included elements, methods of teaching and learning style were principles of teaching and learning model, objective, teaching and learning process and evaluation

- Designing learning activities

- To construct a teaching and learning activities

Phase 3: To study the implementation of the Blended learning model for learning an Information Technology (IT) for life course of undergraduate students at Rajabhat University. Research in this phase aims to Blended learning model for learning Information Technology (IT) for life course to trial students in the sample group follows:

- The sample of 281 of undergraduate students at Surindra Rajabhat University participated in the study and they were randomly assigned to an experimental group with 151 students learned using the developed model and a control group with 130 students learned using the conventional learning approach. These students were selected using a cluster random sampling technique

- Variables studied

- Independent variables 
- Type of learning are Blended learning model and conventional learning approach

- Faculties are science and technology, science management, education and human and social sciences

- Dependent variable are learning achievement, critical thinking and self-directed learning behaviors

- The experiments and collecting data

- Experimental pattern is pretest-posttest control group design

- The experiment

- Explained the purpose of the experimental to students in the sample group, the achievement test, tests of critical thinking and self directed learning behaviors before learning

- The students in the sample group implementation of instructional activities until the end of the lesson. Then the students test after learning achievement, tests of critical thinking and self-directed learning behaviors

- Data collection, the researcher collected data using the experimental research. Collecting data in semester 1,2553 academic year, during 7 June to 8 October, 2010

- Handling and analysis

- Scoring questionnaires and tests, criteria specified. Then the average score and interpretation of average

- The score from all measurements to testing of assumptions and analysis of multiple variance (MANCOVA) in homogeneity of variance, homogeneity of variance-covariance matrices and homogeneity of regression slope, appear the data consistent with the assumptions

- The scores were analyzed to test the hypothesis and proposed tables and descriptive analysis

- The statistics used in this study

- Basic statistic are average, standard deviation and percentage

- The statistics used to analyze the quality of the tests

- Test assumptions, homogeneity of variance used Levene's test statistic, homogeneity of variancecovariance matrices used Box's M method, homogeneity of regression slope used F-test, correlation used Pearson's method

- The statistics used in hypothesis testing, paired t-test, F-test (two-way MANOVA and two-way ANCOVA)

\section{RESULTS}

\section{Effects of Synthetic Blended learning model}

Contextual study: Study learning and teaching Information Technology (IT) for life course, the results showed that learning and teaching issues should be improved were content that is not appropriate for levels and ages of the students, teaching and learning activities that are not diverse do not focus on the students think and solve problems on their own, materials is not enough, lecturer also use the teaching method is the most lecture and then evaluated to measure academic performance most of them have focused only measure of achievement.

Conceptual study: The study documents, related research textbooks, the concepts and principles of a scholar and educator. The researcher analyzed and synthesized elements of Blended learning model follows:

- Elements of the learning model

- Principle of blended learning

- Model objectives

- Organization of learning activities

- Measurement and evaluation

- Elements of the Blended learning model

- Self-learning program

- Class learning using interactive lectures

- Self-learning with on-line lessons

- Effects of the developed Blended learning model

The developed Blended learning model consisted of four components:

- Principle of blended learning

- Element of learning activities of the Blended learning model was composed

- $\quad$ Self-learning program

- Class learning using interactive lectures

- Self-learning with on-line lessons

- Blended learning process using the process learning cycle of learning five step were engagement, exploration, explanation, elaboration, evaluation

Model objectives: The developed Blended learning model purpose to develop learning outcomes of undergraduate students at Rajabhat University.

\section{Organization of learning activities}

Step 1: Before learning, orientation for students to prepare ready for the learning, advice for learning with Blended learning model, demonstrated wide of learning and teaching:

- The teaching and learning have three activities are self-directed learning from courseware, interactive lecture and online learning

- Measurement and evaluation of learning is measure and evaluate authentic learning 


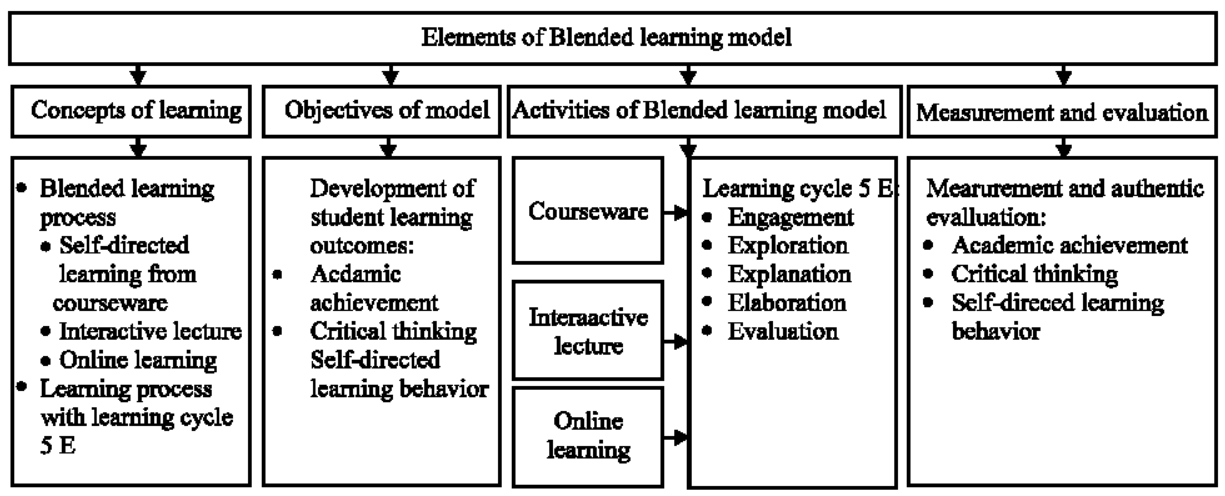

Fig. 1: Elements of Blended learning model

From the learning process of learners, measured by achievement scores, critical thinking and self directed learning behavior. Elements of the developed Blended learning model can be shown in Fig. 1.

\section{Results of the study the implementation of the Blended} learning model: The developed Blended learning model showed an efficiency of 82.07/80.39 and effectiveness index of 0.6527 . The students indicated gains in learning achievement, critical thinking as a whole and in each of five subscales and self-directed learning behaviors as a whole and in each of five subscales from before learning via the developed model $(\mathrm{p}<0.0001)$.

The experimental group students showed more learning achievement, critical thinking in general and in three subscales: inference, recognition of assumptions and evaluation of arguments and self-directed learning behaviors in general and in five subscales than did the control group students $(\mathrm{p}<0.05)$.

\section{DISCUSSION}

Developed the Blended learning model for learning an information technology for life course, there are important issues that should be discussed. The developed Blended learning model for learning information technology for life course of undergraduate students at Rajabhat University had been found higher than the expected effectiveness of $82.07 / 80.39$ that is consistent with the criteria $80 / 80$ and had developed Blended learning model for learning an information technology for life course of undergraduate students at Rajabhat University index of effectiveness 0.6527. Consistent with the findings of Saiseesod (2002)'s research found that model system for teaching using the internet for Rajabhat Institute, effective compliance with the criteria $80 / 80$. The findings appear, this can be explained as follows:
The developed Blended learning model pass step process of creating a system and how appropriate was context study, study principles, theories and research related documents to analyze and synthesize to the elements of blended learning that appropriate to subject and content including the choice of teaching and learning activities that develop critical thinking abilities and focus on self-directed learning behavior, the use of learning cycle 5 step.

The developed Blended learning model has been verified, improve, through appropriate assessment experts in various fields such as experts in curriculum and instruction, measurement and evaluation of learning and computer experts. As a learning model is complete and is more appropriate. So, it can be used in teaching as well.The developed Blended learning model have learning activities. Teaching various for students to practice and learn by themselves freely. The forward guidance teachers to access the content knowledge and practice activities. Students can search the various information, activities and training of critical thinking every time. Students make learning fun and practice activities assigned to the leaves to get more knowledge, it also has measurement and evaluation clear and inform the learning outcomes for learners to be aware of all times. Make the students eager to learn.

The students indicated gains in learning achievement, critical thinking as a whole and in each of five subscales and self-directed learning behaviors as a whole and in each of five subscales from before learning via the developed model $(\mathrm{p}<0.0001)$. Consistent with the findings of Jinjo (2007)'s research found that the students in Rajabhat University have academic achievement scores. After learning more from the previous study at the 0.05 level of significantly.

Suksathid (2007)'s research found that self-directed learning for adult, learning through the web, academic 
achievement, characteristics of self-directed learning after learning increase from before learning at the 0.05 level of significantly. The findings appear, this can be explained as follows:

Information technology for life course is emphasis on both theory and practice. Using the Blended learning model with many activities allow students to learn the full capability. Activities of self-directed learning, interactive lecture and online learning allows students to active learning. Learning is that students participate in learning. Various activities in learning make learning meaningful. This is a way of learning in depth, students will understand and find the meaning of content by linking with the existing experience, identify new knowledge that has been with the knowledge that old. Can be evaluated, build upon and create their own ideas, this is called the learning occurs. This is different from learning how superficial level, focused information and recognize the data only. Students like, this will be the learning who study in learning how to learning, students will learn how to learning, enthusiastic learners, skills that can accept data, analysis and synthesis of information systematically (Suwannatthachote, 2008). Developed the Blended learning model to design learning and teaching activities for students to self-directed learning. Activities have emphasized teaching students the skills of self. Were analys is of their needs, the purpose of learning, planning learning, seeking resources and evaluation study.

The students from different faculties did not differently indicate learning achievement, critical thinking in general and in two subscales: inference and recognition of assumptions. Otherwise, the students from science and technology faculty showed more critical thinking in three subscales: deduction, interpretation and evaluation of arguments than did the students from education faculty and humanities and social sciences faculty and evidenced more self-directed learning behaviors in general and in four subscales, except for the learning evaluation subscale than did those students from other faculties $(\mathrm{p}<0.05)$. The findings appear this can be explained as follows the students under the faculty of science and technology is a student group with the idea of reasoning, good attitude toward science can be used information technology fluency than students of other faculty. As a result, the learning outcomes of higher.

The statistical interactions of learning model and faculties on learning achievement, critical thinking in general and three subscales: deduction, interpretation and evaluation of arguments and self-directed learning behaviors in general and three subscales: formulating learning objectives, planning study and evaluating learning outcomes $(p<0.05)$. The results of this research may be due developed the Blended learning model, design learning activities that focus on teaching students to learn by themselves know that they need to learning what are planning to learning in order to achieve the aims set out, well known evaluate their own learning. In addition to this, teaching and learning activities also focusing on critical thinking for students to study various situation and analysis of situation. Make the students' critical thinking ability increased.

\section{CONCLUSION}

The developed Blended learning model was appropriately efficient and effective for increasing the students' outcomes from before learning and more than the students learned using the conventional learning approach. This model, therefore should be implemented in teaching and learning a course on information technology for life at other Rajabhat Universities.

\section{ACKOWLEDGEMENT}

This research has completed perfectly with a support and kindness of Associate Professor Dr. Chaiyot Ruangsuwan (thesis committee chairman), Associate Professor Dr. Paitool Suksringarm (thesis committee) who have greatly given a useful advice and weakness verification from the beginning till its completion. Eventually, researcher would like to take this opportunity to give them very much of researcher's appreciation and thank you indeed.

\section{REFFERENCES}

Jinjo, S., 2007. Development of a blended learning model for computer programming language in business computer study. Ph.D. Thesis, King Mongkut's University of Technology North Bangkok.

Jongchaikit, M., 2003. E-learning and learning in school. J. Sci. Educ. Math. Technol., 31: 12-18.

Saiseesod, S., 2002. The development of a web-based instruction model for rajabhat institutes. Ph.D. Thesis, Srinakharinwirot University, Bangkok, Thailand.

Suksathid, W., 2007. Promoting self-directed learning for adult learners by web-based learning. Ph.D. Thesis, Srinakharinwirot University, Bangkok, Thailand.

Suwannatthachote, P., 2008. Active Learning. Faculty of Education, Chulalongkorn University Press, Thailand. 